\title{
Unique Reaction Path in Heterogeneous Catalysis: The Concerted Semi-Hydrogenation of Propyne to Propene on $\mathrm{CeO}_{2}$
}

\author{
Max García-Melchor,* Luca Bellarosa, and Núria López \\ Institute of Chemical Research of Catalonia (ICIQ), Av. Països Catalans, 16, E-43007 Tarragona, Spain
}

Supporting Information

ABSTRACT: Despite its ubiquity in homogeneous and enzymatic catalysis, concerted mechanisms have been overlooked for heterogeneously catalyzed reactions. The elusive nature of transition states leaves Density Functional Theory, DFT, as the only robust tool for their identification and characterization. By means of this method, we show that a concerted path takes part in the recently discovered semihydrogenation of propyne on $\mathrm{CeO}_{2}$, for which an excellent activity and selectivity have been reported. The high surface $\mathrm{H}$ coverage imposed by the experimental hydrogenation conditions induces site isolation and drives the reaction through a six-membered ring transition state. This unprecedented pathway accounts for many of the experimental observations, such as the unique syn-stereoselectivity, the excellent alkene selectivities, or the high temperature and large $\mathrm{H}_{2}$ /alkyne ratios required.

KEYWORDS: hydrogenation, $\mathrm{CeO}_{2} \mathrm{H}_{2}$ activation, DFT, reaction mechanisms, alkynes, olefins, concerted

\section{INTRODUCTION}

The reaction mechanisms that operate in metal-based heterogeneous catalysis imply the coordination of reactants to the metal surface followed by elementary steps consisting in single atom-by-atom transfers (forming/breaking only one bond). ${ }^{1,2}$ This is at odds with gas-phase, homogeneous, and enzymatic catalysis, where concerted mechanisms involving the addition of more than one atom at a time are ubiquitous. In the present work, we show that these paths are not forbidden in heterogeneous reactions, but rather, they require specific catalytic environments and surface ensembles to come out. For this study, we have focused on one of the most relevant reactions in heterogeneous catalysis: the partial hydrogenation of alkynes shown in eq 1 .

$$
\mathrm{R}-\mathrm{C} \equiv \mathrm{C}-\mathrm{H} \quad \underset{\mathrm{H}}{\stackrel{\text { Catalyst }}{\mathrm{H}_{2}}} \underset{\mathrm{R}}{\mathrm{R}}-\underset{\mathrm{H}}{\mathrm{H}}=\underset{\mathrm{H}}{\mathrm{H}}=\underset{\mathrm{H}}{\mathrm{C}}-\mathrm{H}
$$

Over the last decades, alkyne semihydrogenation has attracted great attention due to its primary role in the purification of rich olefin streams in oil refineries and its potential for the large scale production of commodity chemicals. ${ }^{3,4}$ This reaction is traditionally carried out by different formulations of $\mathrm{Pd}$ catalysts, ${ }^{5-7}$ though it can also take place with poorer activities on other active metals ${ }^{8}$ or on $\mathrm{Au}^{9}$ and $\mathrm{Ag}^{10}$ nanoparticles. The added advantage of Pd-based catalysts is that they provide high activities at moderate temperatures and hydrogen pressures; however, they suffer from selectivity losses, namely, overhydrogenation and oligomerization reactions. ${ }^{4,9}$ To overcome this issue, numerous experimental and theoretical works have analyzed factors that affect the selectivity of catalysts, including particle size, ${ }^{6}$ the presence of subsurface species, ${ }^{11-15}$ and the addition of modifiers or promoters. ${ }^{16-18}$ At the same time, the replacement of noble metals with more economical substitutes has been also a subject of intensive research. ${ }^{19,20}$

Very recently, ceria has been proven to catalyze the partial hydrogenation of alkynes with excellent selectivities, between 71 and $91 \%$, at high degrees of conversion. ${ }^{21,22}$ The optimal reaction conditions for this new catalytic system require a relatively high temperature $(T=523 \mathrm{~K})$ and a large $\mathrm{H}_{2}$ /alkyne ratio $(30: 1)$, which has been attributed to the inherent difficulty of $\mathrm{CeO}_{2}$ in activating $\mathrm{H}_{2}{ }^{21-23}$ This unprecedented activity of a metal oxide in hydrogenation, coupled with the fact that reaction mechanisms on these materials might divert from those on metals ${ }^{24}$ due to their acid-base properties, ${ }^{25}$ opens new scenarios for the activation of selected bonds.

The quintessential hydrogenation mechanism involving metal surfaces is the Horiuti-Polanyi or dissociative mechanism (Scheme 1), which was proposed in $1934 .^{26}$ It entails the homolytic dissociation of $\mathrm{H}_{2}$ on the catalyst surface followed by the sequential addition of $\mathrm{H}$ atoms to the adsorbed alkyne. This mechanism operates not only on regular surfaces of active metals like $\mathrm{Pd}^{27}$ or $\mathrm{Ni}^{28}$ but also on low-coordinated sites of the less active $\mathrm{Au}$ nanoparticles. ${ }^{29}$ Alternatively, for catalysts that are not able to break $\mathrm{H}_{2}$, the associative mechanism depicted in Scheme 1 sets in. In this case, the $\mathrm{H}-\mathrm{H}$ bond is directly activated by the adsorbed alkyne and the metal surface, which 
Scheme 1. Possible Reaction Mechanisms for the Partial Hydrogenation of Alkynes in Heterogeneous Processes

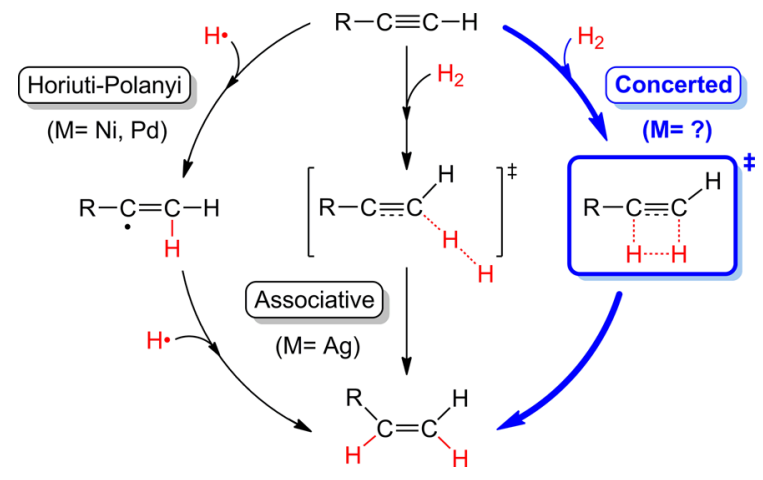

results in the incorporation of a $\mathrm{H}$ atom to these two fragments. Subsequently, the surface $\mathrm{H}$ is directly transferred to the alkyne yielding the desired olefin. An example of this associative mechanism is the recently reported propyne to propene conversion on $\mathrm{Ag}$ nanoparticles. ${ }^{10}$

A third hydrogenation mechanism, for which there is no experimental or computational evidence to date, consists in the simultaneous addition of two $\mathrm{H}$ atoms to the adsorbed alkyne. This concerted mechanism (Scheme 1) resembles both the acid-base-like mechanism involved in the hydroboration of double and triple carbon bonds, ${ }^{30}$ and the one in pericyclic reactions. $^{31}$ Thus, its operation under certain reaction conditions cannot be ruled out.

Herein, we present a thorough mechanistic study on the recently discovered semihydrogenation of propyne catalyzed by $\mathrm{CeO}_{2} .{ }^{21} \mathrm{We}$ found that the surface coverage under the experimental hydrogenation conditions drives the reaction toward the concerted path highlighted in the blue square of Scheme 1 . This unprecedented mechanism accounts for many of the experimental observations, such as the unique synstereoselectivity, the excellent alkene selectivities, or the high temperature and large $\mathrm{H}_{2}$ /alkyne ratios required, ${ }^{21}$ and furthermore, the mechanism may provide insight on the structure sensitivity recently observed. ${ }^{32}$

\section{COMPUTATIONAL METHODS}

The reaction mechanism for the $\mathrm{CeO}_{2}$-catalyzed semihydrogenation of propyne under relevant experimental conditions were investigated by means of DFT as implemented in the VASP code, version 5.3.2..$^{33,34}$ In all the calculations, the core electrons of $\mathrm{Ce}, \mathrm{C}$, and $\mathrm{O}$ atoms were replaced by projectoraugmented wave potentials, ${ }^{35}$ whereas their valence electrons were expanded in plane waves with a kinetic energy cutoff of $500 \mathrm{eV}$. In order to describe the strongly correlated character of the Ce-4f orbitals correctly, a Hubbard $U$-like term was added to the Perdew-Burke-Ernzenhof functional. ${ }^{36}$ This was carried out following the $\mathrm{DFT}+U$ approach of Dudarev et al., ${ }^{37}$ which defines the difference between the Coulomb and exchange energy terms as the effective $U$ parameter, $U_{\text {eff. }}$ This parameter was set to $4.5 \mathrm{eV}$, as proposed by Fabris et al. ${ }^{38}$

The optimized lattice parameter of ceria using a $\Gamma$-centered 7 $\times 7 \times 7$ k-point grid was $a_{\text {calc }}=5.497 \AA$, which is in good agreement with the experimental value of $a_{\exp }=5.411 \AA .{ }^{39}$ The $\mathrm{CeO}_{2}$ catalyst was modeled as slabs containing nine atomic layers of the most exposed (111) facet and a vacuum space of at least $10 \AA$. The atoms in $p(2 \times 2)$ supercells were optimized using a $\Gamma$-centered $3 \times 3 \times 1 \mathrm{k}$-point mesh and keeping only the four bottom layers fixed to their bulk positions. Total energies reported throughout this manuscript were converged better than $10^{-5} \mathrm{eV}$ in the self-consistent field, and geometries were relaxed until the energy threshold of $10^{-4} \mathrm{eV}$ was fulfilled. Spin-polarized calculations were carried out when needed, and a careful analysis of all the possible open-shell spin states was performed (Table S1).

To locate transition states, we used the Improved Dimer Method $^{40}$ (IDM) and the Climbing Image Nudged Elastic Band $^{41}$ (CI-NEB) algorithms. For the latter, at least five images along the reaction coordinate were employed. The nature of all stationary points was confirmed by performing frequency a)

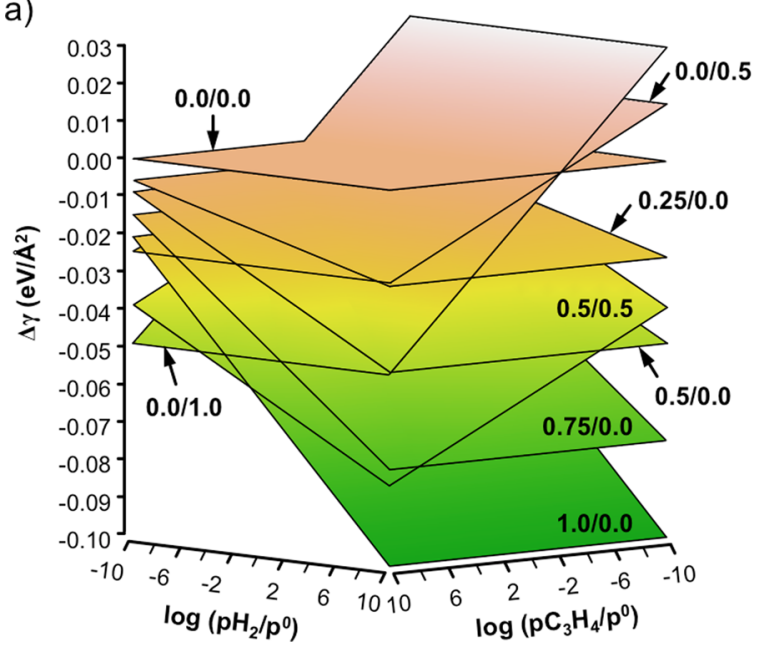

b)

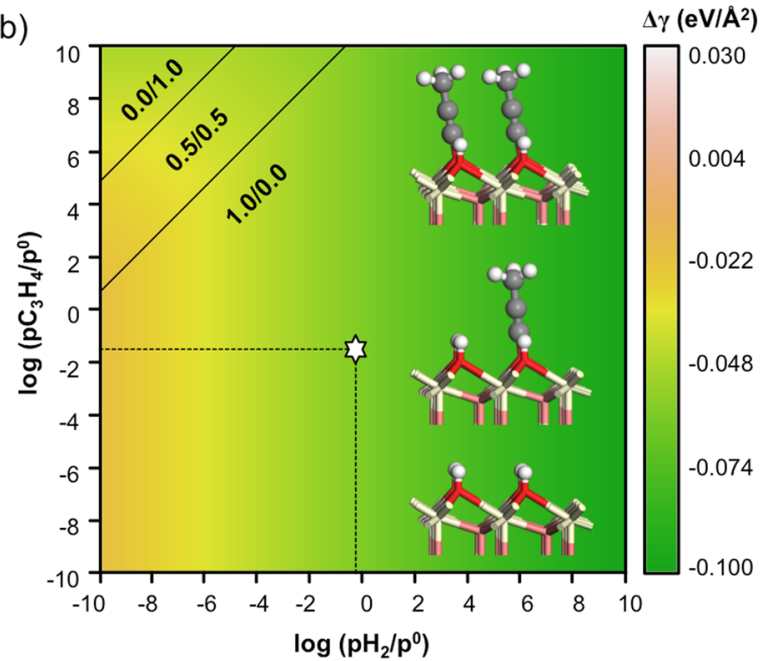

Figure 1. Tridimensional (a) and bidimensional perspectives (b) of the relative free energy surface of $\mathrm{CeO}_{2}(111)$ as a function of the $\mathrm{H}_{2}$ and $\mathrm{C}_{3} \mathrm{H}_{4}$ pressures at the experimental reaction temperature, $T=523 \mathrm{~K}$. Free energies are calculated taking the clean $\mathrm{CeO}_{2}(111)$ surface and the $\mathrm{H}_{2}$ and $\mathrm{C}_{3} \mathrm{H}_{4}$ gas molecules as reference (see Supporting Information for details). A star marks the region corresponding to the optimal pressures reported in experiments. Insets of the most representative surfaces are also shown. Color code: Ce (pale yellow), surface O (red), subsurface O (pale red), C (silver), and $\mathrm{H}$ (white). 
analysis with a numerical Hessian matrix obtained by atomic displacements of $0.02 \AA$.

For the most relevant steps, the $\mathrm{PBE}+U$ methodology was benchmarked against the HSE06 hybrid functional. ${ }^{42}$ As these calculations are much more time-consuming, they were performed with a reduced cutoff of $400 \mathrm{eV}$ and at the $\Gamma-$ point. The HSE06 results presented in Table S2 confirm the good performance (within $0.15 \mathrm{eV}$ ) of the $\mathrm{PBE}+U$ methodology for this catalytic system.

\section{RESULTS AND DISCUSSION}

The reported strong dependence of propene selectivity on the hydrogen/propyne feed $^{21}$ suggests that hydrogenation on $\mathrm{CeO}_{2}$ is severely affected by the surface coverage. Hence, we first investigated the $\mathrm{CeO}_{2}(111)$ surface termination as a function of the $\mathrm{H}_{2}$ and $\mathrm{C}_{3} \mathrm{H}_{4}$ gas phase reservoirs. To this aim, we explored the most representative configurations that might result from the interaction of those gases with $\mathrm{CeO}_{2}$, and we analyzed them by means of ab initio thermodynamics. ${ }^{43}$

Although impeded by a sizable barrier of $1.08 \mathrm{eV}, \mathrm{H}_{2}$ dissociates on $\mathrm{CeO}_{2}$ leading to the hydroxylation of the surface and releasing more than $2 \mathrm{eV} /$ molecule. ${ }^{24}$ Thus, we considered several $\mathrm{H}$ coverages ranging from 0.25 to $1.0 \mathrm{ML}$ as the most likely configurations resulting from that interaction. Similarly, calculations on the homolytic dissociation of propyne to form $\mathrm{O}-\mathrm{H}$ and $\mathrm{O}-\mathrm{CCCH}_{3}$ surface terminations revealed that this is an exothermic process by $1.7 \mathrm{eV} /$ molecule. Conversely, the heterolytic dissociation leading to an $\mathrm{O}-\mathrm{H}$ and $\mathrm{Ce}-\mathrm{CCCH}_{3}$ coverage was found to be endothermic by $0.43 \mathrm{eV}$. Therefore, only coverages of the homolytically dissociated $\mathrm{C}_{3} \mathrm{H}_{4}$ were selected as representative configurations for the interaction of this gas with $\mathrm{CeO}_{2}$. In particular, we examined the coverages corresponding to the dissociation of one and two $\mathrm{C}_{3} \mathrm{H}_{4}$ molecules, 0.5 and $1.0 \mathrm{ML}$, respectively.

In order to account for the interaction of both gases with $\mathrm{CeO}_{2}$, a mixed coverage of $0.5 \mathrm{ML}$ of $\mathrm{H}$ and $0.5 \mathrm{ML}$ of $\mathrm{C}_{3} \mathrm{H}_{4}$ was also considered. It should be noted that in all the selected surfaces, the electrons from the cleaved sigma bonds are transferred directly to the lattice, which causes the partial reduction of the metal ions from $\mathrm{Ce}^{4+}$ to $\mathrm{Ce}^{3+}$. For these configurations, we calculated all the possible open-shell spin states (Table S1) and found that all these states are (almost) degenerate. This was also noted by Ganduglia-Pirovano et al. ${ }^{44}$ and in other works cited therein. The results derived from the $\mathrm{ab}$ initio thermodynamics on all these structures are summarized in the three-dimensional plot presented in Figure 1a. In this graphic, the most likely coverage at the given $\mathrm{H}_{2}$ and $\mathrm{C}_{3} \mathrm{H}_{4}$ partial pressures and the reaction temperature of $523 \mathrm{~K}$ corresponds to that with the lowest relative free energy surface, $\Delta \gamma$. This can be more easily identified by inspecting the twodimensional projection shown in Figure $1 b$.

According to the relative free surface energies reported in Figure 1, up to three different coverages might exist within the range of the considered pressures. More specifically, for very low $\mathrm{H}_{2} / \mathrm{C}_{3} \mathrm{H}_{4}$ ratios, the full coverage of the homolytically dissociated $\mathrm{C}_{3} \mathrm{H}_{4}(0.0 / 1.0 \mathrm{ML})$ is the most likely, whereas for low ratios, a mixed coverage of $\mathrm{H}$ and $\mathrm{C}_{3} \mathrm{H}_{4}(0.5 / 0.5 \mathrm{ML})$ is expected. On the other hand, Figure 1 suggests that, from relatively high to very high $\mathrm{H}_{2} / \mathrm{C}_{3} \mathrm{H}_{4}$ ratios, a fully hydroxylated surface $(1.0 / 0.0 \mathrm{ML})$ with all the $\mathrm{Ce}$ atoms reduced prevails (Figure S1). This termination spreads across a wide range of gas pressures, including those used in experiments. ${ }^{21}$ We used this surface coverage, corresponding to the resting state, as the starting point for our investigation of the operative hydrogenation mechanism.

It is important to note that, with the $\mathrm{CeO}_{2}$ catalyst completely hydroxylated, only the acidic $\mathrm{Ce}$ sites from the surface are accessible for further reactivity. This resting state not only reduces the number of potential mechanisms for hydrogenation but also implies that propyne (or hydrogen) can only adsorb on top of the $\mathrm{Ce}^{3+}$ ions. This high surface occupation blocks the adsorption of adjacent alkynes and limits its diffusion, thus avoiding the formation of oligomers and leaving overhydrogenation as the only selectivity-compromising route.

The interaction between $\mathrm{C}_{3} \mathrm{H}_{4}$ and the resting state of $\mathrm{CeO}_{2}$ is rather weak, as the binding energy lower than $0.10 \mathrm{eV}$ demonstrates. Test calculations indicate that the inclusion of $\mathrm{vdW}$ interactions stabilizes adsorbates by $\sim 0.1 \mathrm{eV}$. These contributions, however, may affect all the other species involved in the reaction mechanism by a rather constant amount, and thus they do not affect the present conclusions. Similarly, $\mathrm{H}_{2}$ can also molecularly adsorb on a neighboring $\mathrm{Ce}^{3+}$ center. In this case, however, the $\mathrm{H}_{2}-\mathrm{CeO}_{2}$ interaction is even less exothermic than that with $\mathrm{C}_{3} \mathrm{H}_{4}$, which explains why a large $\mathrm{H}_{2} / \mathrm{C}_{3} \mathrm{H}_{4}$ feed is required in the optimal reaction conditions. Interestingly, the proximity of the two adsorbed gases in this structure suggests the simultaneous addition of $\mathrm{H}_{2}$ to $\mathrm{C}_{3} \mathrm{H}_{4}$ (Scheme 1) as a plausible hydrogenation mechanism. In fact, two variants of this concerted path can be envisaged (Scheme 2 ). The first one involves the concurrent transfer of the two

Scheme 2. Schematic Representation of the (a) Four- and (b) Six-Membered Ring Transition States Proposed for the Semi-Hydrogenation of Propyne a)

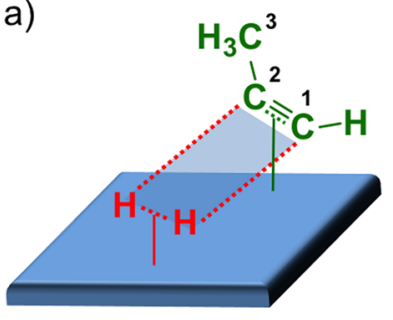

b)

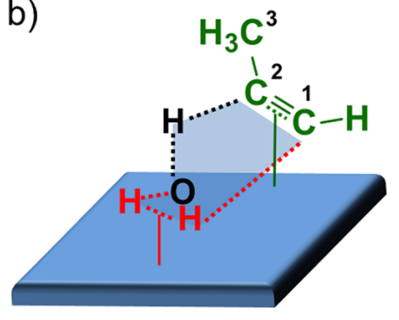

hydrogens in $\mathrm{H}_{2}$ via a cyclic transition state constituted by these atoms and the $\mathrm{C}_{1}$ and $\mathrm{C}_{2}$ from $\mathrm{C}_{3} \mathrm{H}_{4}$ (Scheme 2a). This transition state structure was located and is presented in Figure 2. The optimized structure features a much shorter $\mathrm{C}_{1}-\mathrm{H}$ distance compared to the $\mathrm{C}_{2}-\mathrm{H}$ one, and a rather elongated $\mathrm{H}-\mathrm{H}$ bond. Thus, this concerted step can be considered as a nonsynchronous-like process according to the different extension of $\mathrm{C}-\mathrm{H}$ bond formation. To gain a deeper insight into the reactivity within this transition state, we calculated the charge density difference in this species, as shown in Figure 2. According to this representation, the $\mathrm{H}$ nearest to the $\mathrm{C}_{1}$ is transferred as a hydride, whereas the second $\mathrm{H}$ is added to the $\mathrm{C}_{2}$ as a proton. Unfortunately, the calculated energy for this transition state, $3.43 \mathrm{eV}$, is too high to be operative at the experimental temperature of $523 \mathrm{~K}$.

The second concerted pathway consists in incorporating one $\mathrm{H}$ atom from the adsorbed $\mathrm{H}_{2}$ and one $\mathrm{H}$ atom from a nearby $\mathrm{O}-\mathrm{H}$ lattice to the organic moiety (Scheme $2 \mathrm{~b}$ ). Thus, the transition state associated with this mechanism corresponds to a six-membered ring structure that includes the adsorbed $\mathrm{H}_{2}$, the $\mathrm{C}_{1}$ and $\mathrm{C}_{2}$ from $\mathrm{C}_{3} \mathrm{H}_{4}$, and an $\mathrm{O}-\mathrm{H}$ group from the surface. 


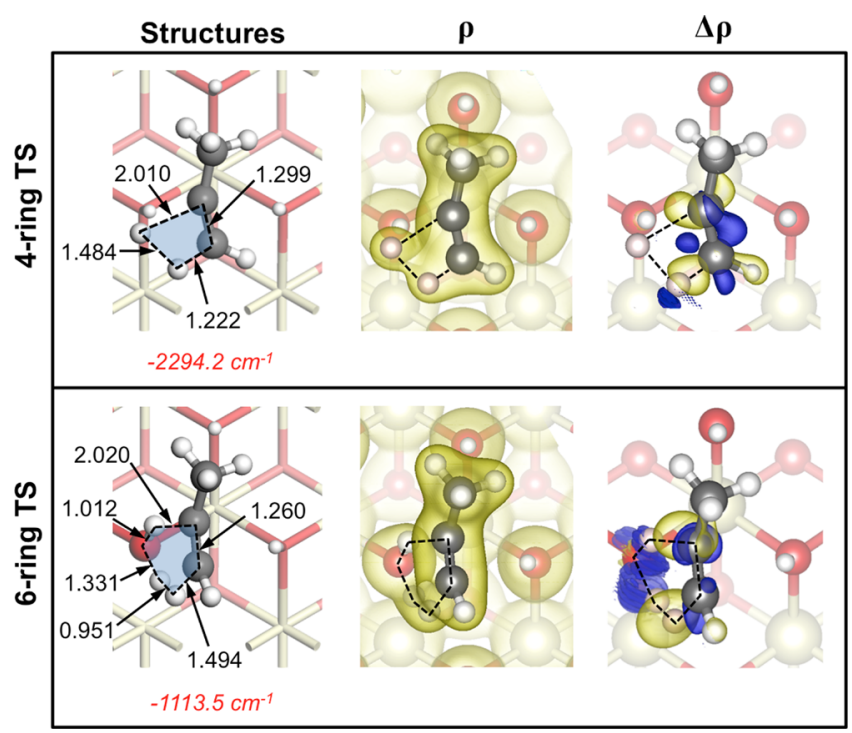

Figure 2. Top views of the optimized structures, total charge density, charge density difference, and imaginary frequencies (in red) for the four- and six-membered ring transition states. The charge density difference was calculated with respect to the isolated $\mathrm{H}_{2}, \mathrm{C}_{3} \mathrm{H}_{4}$, and $\mathrm{CeO}_{2}$ fragments at the transition state geometries. Yellow (blue) isosurfaces indicate accumulation (depletion) of the charge density.

This transition state structure was also located and is shown in Figure 2. As in the above four-membered structure, the representation of the charge density difference in this species clearly indicates that the closest $\mathrm{H}$ to the $\mathrm{C}_{1}$ is added as a hydride. However, in this case, the other $\mathrm{H}$ atom in $\mathrm{H}_{2}$ coordinates to a nearby $\mathrm{O}-\mathrm{H}$ lattice at the same time that the proton from this group is abstracted by the $C_{2}$. The calculated energy for this nonsynchronous transition state, corrected by the zero-point vibrational energy, is $1.88 \mathrm{eV}$. This value is significantly lower than that for the four-membered ring transition state, which makes this pathway plausible under the experimental conditions. It is worth mentioning that the entropic requirements of the concerted transition state are abated by both the high $\mathrm{H}$-coverage on the surface that limits the possible interactions of the incoming $\mathrm{H}_{2}$ molecules and the strong templating effect of the surface ensembles that leads to the formation of a six-membered ring transition state. Furthermore, this energy is $\sim 1 \mathrm{eV}$ lower than the one reported earlier for the semihydrogenation of acetylene and based on a Horiuti-Polanyi-like mechanism. $^{22}$ This difference at the experimental temperature of $523 \mathrm{~K}$ represents a rate increase of more than 9 orders of magnitude, confirming the only operation of the concerted hydrogenation mechanism.

To shed light on the preeminence of the six-membered transition state over the four-membered one, we next performed an activation-strain analysis on these two structures (Table S3). ${ }^{45}$ In this type of analysis, the transition state energies are decomposed as $E_{\mathrm{TS}}=E_{\text {dist }}+E_{\text {int }}$, where $E_{\text {dist }}$ and $E_{\text {int }}$ are the distortion and interaction energies, respectively. The $E_{\text {dist }}$ can be understood as the energy cost associated with the geometric distortion of the $\mathrm{CeO}_{2}, \mathrm{H}_{2}$ and $\mathrm{C}_{3} \mathrm{H}_{4}$ fragments from their structure as isolated species to their "strained" geometries in the transition state. On the other hand, $E_{\text {int }}$ stands for the energy gain arising from the interaction of those fragments with each other in the transition state. Interestingly, the calculated $E_{\text {dist }}$ terms were found to be rather similar for the two cyclic structures, with the $\mathrm{CeO}_{2}$ fragment exhibiting the highest energy difference in favor of the four-membered structure $\left(\left|\Delta E_{\text {dist }}\right| \approx 0.15 \mathrm{eV}\right)$. This can be rationalized with the fact that the six-membered transition state involves an $\mathrm{O}-\mathrm{H}$ group from the $\mathrm{CeO}_{2}$ surface, and therefore, the geometric distortion of this fragment requires a higher energy. Nevertheless, the largest difference between the two transition states resulted to be in the $E_{\text {int }}$ term $\left(\left|\Delta E_{\text {int }}\right| \approx 4 \mathrm{eV}\right)$, which indicates that the preeminence of the six-membered geometry mainly originates from the templating surface effects.

Overall, the results presented so far provide firm theoretical evidence that the partial hydrogenation of propyne on $\mathrm{CeO}_{2}$ occurs through the concerted mechanism summarized in Figure 3. It starts with a completely hydroxylated $\mathrm{CeO}_{2}(111)$ surface,

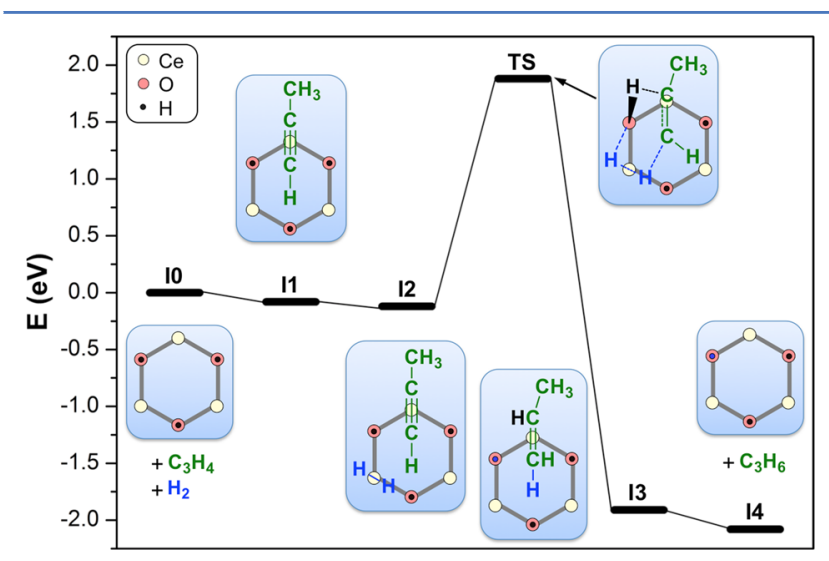

Figure 3. Overall reaction energy profile for the selective hydrogenation of propyne. For the sake of clarity, the fully hydroxylated $\mathrm{CeO}_{2}(111)$ surface is represented by a gray hexagon, where the $\mathrm{Ce}, \mathrm{O}$, and $\mathrm{H}$ surface atoms are depicted as pale yellow, red, and black spheres, respectively. The energy of TS has been corrected by the ZPVE.

followed by the sequential adsorption of $\mathrm{C}_{3} \mathrm{H}_{4}$ and $\mathrm{H}_{2}$ on top of two surface $\mathrm{Ce}^{3+}$ ions that leads to $\mathbf{I} \mathbf{1}$ and $\mathbf{I} 2$, respectively. Then, $\mathbf{I} 2$ undergoes concerted hydrogenation of the adsorbed $\mathrm{C}_{3} \mathrm{H}_{4}$ via a six-membered ring transition state (TS). This step results in I3, from which the alkene readily desorbs in an exothermic process. The highest energy point in the overall energy profile corresponds to TS. Therefore, the concerted addition of the two $\mathrm{H}$ atoms to the alkyne is the ratedetermining step.

For completeness, we also investigated the subsequent (over)hydrogenation of propene to propane, see Supporting Information. In this case, the presence of two additional $\mathrm{H}$ atoms in the adsorbed alkene frustrates a concerted transition state and causes the reaction to occur in two steps: first, the $\mathrm{H}$ from the surface $\mathrm{OH}$ group is transferred to the $\mathrm{C}_{2}$ of the olefin, and then, the adsorbed $\mathrm{H}_{2}$ dissociates heterolytically regenerating the surface $\mathrm{OH}$ and yielding the final alkane. The first step is the most energy demanding with an energy barrier of $2.69 \mathrm{eV}$. This energy is significantly higher than the $1.88 \mathrm{eV}$ required for the hydrogenation of propyne to propene, which explains the excellent selectivities obtained in experiments by kinetic arguments. Importantly, the energy of the transition state associated with the overhydrogenation of propene, 2.69 $\mathrm{eV}$, is even lower than that reported for the hydrogenation of acetylene to ethylene via a Horiuti-Polanyi mechanism, 2.86 $\mathrm{eV}^{22}$

The concerted mechanism presented in Figure 3 also accounts for the rest of experimental observations. ${ }^{21}$ For 
example, the increasing alkene selectivity with the $\mathrm{H}_{2} / \mathrm{C}_{3} \mathrm{H}_{4}$ ratio can be attributed to the full $\mathrm{H}$ coverage that prevents the adsorption of alkyne molecules in adjacent positions and hinders its diffusion along the surface avoiding the formation of byproducts by oligomerization. The detrimental effect of oxygen vacancies on the catalytic activity can be also explained by the reduction of the number of active sites, as surface $\mathrm{O}$ atoms have been shown to play an active role in the hydrogenation transition state. Hence, a reduced catalytic activity should be expected when increasing the number of oxygen vacancies (e.g., by doping the $\mathrm{CeO}_{2}$ surface) ${ }^{46}$ Besides, the concerted mechanism ensures a unique syn-stereoselectivity, in agreement with the experiments, ${ }^{21,22,47}$ and the delicate ensemble requirements might explain the recently reported structure sensitivity. ${ }^{32}$

\section{CONCLUSIONS}

In summary, the DFT calculations reported in this work show that the resting state of the $\mathrm{CeO}_{2}$ catalyst in the semihydrogenation of propyne is decisive to understand its outstanding activity and sharp selectivity. We found that it corresponds to a fully hydroxylated and fully reduced surface, where the adsorbed $\mathrm{H}$ atoms play a two-fold role: they act as a hydrogen source for hydrogenation and further prevent the formation of oligomers by limiting the adsorption and diffusion of alkyne molecules. The full $\mathrm{H}$ coverage opens the way for an unprecedented concerted hydrogenation mechanism. The energy barrier for this path is about $1 \mathrm{eV}$ lower than the Horiuti-Polanyi mechanism previously proposed for the hydrogenation of acetylene on $\mathrm{CeO}_{2}$, and only leads to the syn-product in agreement with experiments. Therefore, the appearance of concerted pathways should be considered in future mechanistic studies on surfaces. This finding increases the list of hydrogenation paths and, accordingly, broadens the possibilities in the future design of more efficient and economic catalysts.

Finally, we would like to point out that the preeminence of Density Functional Theory to unravel complex mechanisms is further reinforced by the fact that even kinetic data, typically employed to determine reaction orders and afterward infer the mechanism, ${ }^{10}$ might not be conclusive. Our kinetic analysis, see Supporting Information, indicates that both $\mathrm{H}_{2}$ and $\mathrm{C}_{3} \mathrm{H}_{4}$ reaction orders for the concerted hydrogenation mechanism should lay between -1 and 1 , and thus, partially overlap with the values for a Horiuti-Polanyi mechanism, which does not allow further mechanistic considerations.

\section{ASSOCIATED CONTENT}

\section{S Supporting Information}

Details on the $\mathrm{ab}$ initio thermodynamics, energies of the surface configurations with different open-shell spin states, benchmark calculations with the HSE06 hybrid functional, spin densities on the surface $\mathrm{Ce}^{3+}$ ions of the $\mathrm{CeO}_{2}$ resting state structure, activation-strain analysis, fractional coordinates for the four and six-membered ring transition states, derived kinetic equations, and optimized structure for the highest energy transition state involved in the (over)hydrogenation of propene.

\section{AUTHOR INFORMATION}

\section{Corresponding Author}

*E-mail: maxgarcia@iciq.es, maxg@slac.stanford.edu. Fax: (+34) 977920231. Tel: (+34) 977920200.

\section{Notes}

The authors declare no competing financial interest.

\section{ACKNOWLEDGMENTS}

We thank EU (ERC-2010-StG-258406) and MINECO (CTQ2012-33826/BQU) for financial support and BSC-RES for providing generous access to their computational resources. We also thank Moisés Álvarez Moreno for technical support.

\section{REFERENCES}

(1) Abild-Pedersen, F.; Greeley, J.; Studt, F.; Rossmeisl, J.; Munter, T. R.; Moses, P. G.; Skúlason, E.; Bligaard, T.; Nørskov, J. K. Phys. Rev. Lett. 2007, 99, 016105.

(2) Nørskov, J. K.; Bligaard, T.; Rossmeisl, J.; Christensen, C. H. Nat. Chem. 2009, 1, 37-46.

(3) Derrien, M. L. In Catalytic Hydrogenation; Červený, L., Ed.; Elsevier: Amsterdam, 1986; Vol. 27, pp 613-666.

(4) Bond, G. C. Metal-Catalysed Reactions of Hydrocarbons; Springer: New York, 2005; Vol. 21, pp 395-436.

(5) Borodziński, A.; Bond, G. C. Catal. Rev. 2006, 48, 91-144.

(6) Borodziński, A.; Bond, G. C. Catal. Rev. 2008, 50, 379-469.

(7) Arnold, H.; Döbert, F.; Gaube, J. In Handbook of Heterogeneous Catalysis; Wiley-VCH Verlag GmbH \& Co. KGaA: Weinheim, 2008; pp 3266-3284.

(8) Crespo-Quesada, M.; Cárdenas-Lizana, F.; Dessimoz, A.-L.; KiwiMinsker, L. ACS Catal. 2012, 2, 1773-1786.

(9) Mitsudome, T.; Kaneda, K. Green Chem. 2013, 15, 2636-2654.

(10) Vilé, G.; Baudouin, D.; Remediakis, I. N.; Copéret, C.; López, N.; Pérez-Ramírez, J. Chem CatChem 2013, 5, 3750-3759.

(11) Teschner, D.; Borsodi, J.; Wootsch, A.; Révay, Z.; Hävecker, M.; Knop-Gericke, A.; Jackson, S. D.; Schlögl, R. Science 2008, 320, 86-89.

(12) Teschner, D.; Révay, Z.; Borsodi, J.; Hävecker, M.; KnopGericke, A.; Schlögl, R.; Milroy, D.; Jackson, S. D.; Torres, D.; Sautet, P. Angew. Chem., Int. Ed. 2008, 47, 9274-9278.

(13) Teschner, D.; Borsodi, J.; Kis, Z.; Szentmiklósi, L.; Révay, Z.; Knop-Gericke, A.; Schlögl, R.; Torres, D.; Sautet, P. J. Phys. Chem. C 2010, 114, 2293-2299.

(14) Studt, F.; Abild-Pedersen, F.; Bligaard, T.; Sørensen, R. Z.; Christensen, C. H.; Nørskov, J. K. Angew. Chem., Int. Ed. 2008, 47, 9299-9302.

(15) Armbrüster, M.; Behrens, M.; Cinquini, F.; Föttinger, K.; Grin, Y.; Haghofer, A.; Klötzer, B.; Knop-Gericke, A.; Lorenz, H.; Ota, A.; Penner, S.; Prinz, J.; Rameshan, C.; Révay, Z.; Rosenthal, D.; Rupprechter, G.; Sautet, P.; Schlögl, R.; Shao, L.; Szentmiklósi, L.; Teschner, D.; Torres, D.; Wagner, R.; Widmer, R.; Wowsnick, G. ChemCatChem 2012, 4, 1048-1063.

(16) Molnár, Á.; Sárkány, A.; Varga, M. J. Mol. Catal. A 2001, 173, 185-221.

(17) Vilé, G.; Almora-Barrios, N.; Mitchell, S.; López, N.; PérezRamírez, J. Chem.-Eur. J. 2014, 20, 5926-5937.

(18) García-Mota, M.; Bridier, B.; Pérez-Ramírez, J.; López, N. J. Catal. 2010, 273, 92-102.

(19) Armbrüster, M.; Kovnir, K.; Friedrich, M.; Teschner, D.; Wowsnick, G.; Hahne, M.; Gille, P.; Szentmiklósi, L.; Feuerbacher, M.; Heggen, M.; Girgsdies, F.; Rosenthal, D.; Schlögl, R.; Grin, Y. Nat. Mater. 2012, 11, 690-693.

(20) Studt, F.; Abild-Pedersen, F.; Bligaard, T.; Sørensen, R. Z.; Christensen, C. H.; Nørskov, J. K. Science 2008, 320, 1320-1322.

(21) Vilé, G.; Bridier, B.; Wichert, J.; Pérez-Ramírez, J. Angew. Chem. Int. Ed. 2012, 51, 8620-8623.

(22) Carrasco, J.; Vilé, G.; Fernández-Torre, D.; Pérez, R.; PérezRamírez, J.; Ganduglia-Pirovano, M. V. J. Phys. Chem. C 2014, 118, $5352-5360$

(23) We noted that this statement, made by the authors of ref 22 , is not consistent with the energy barriers reported therein, as the most energy demanding step corresponds to the addition of the second $\mathrm{H}$ atom to the organic moiety $(2.86 \mathrm{eV})$ and not the initial $\mathrm{H}_{2}$ dissociation $(1.00 \mathrm{eV})$. 
(24) García-Melchor, M.; López, N. J. Phys. Chem. C 2014, 118, $10921-10926$

(25) Metiu, H.; Chrétien, S.; Hu, Z.; Li, B.; Sun, X. J. Phys. Chem. C 2012, 116, 10439-10450.

(26) Horiuti, I.; Polanyi, M. Trans. Faraday Soc. 1934, 30, 11641172.

(27) Mei, D.; Sheth, P. A.; Neurock, M.; Smith, C. M. J. Catal. 2006, $242,1-15$.

(28) Bridier, B.; López, N.; Peréz-Ramírez, J. Dalton Trans. 2010, 39, $8412-8419$.

(29) Segura, Y.; López, N.; Pérez-Ramírez, J. J. Catal. 2007, 247, 383-386.

(30) Macomber, R. S. Organic Chemistry Vol. II: Chemical Behavior of Organic Compounds and Multi-step Organic Synthesis; University Science Books: Mill Valley, CA, 1996; pp 58-103.

(31) Sankararaman, S. Pericyclic Reactions: A Textbook: Reactions, Applications and Theory; Wiley-VCH: London, 2005; pp 1-432.

(32) Vilé, G.; Colussi, S.; Krumeich, F.; Trovarelli, A.; Pérez-Ramírez, J. Angew. Chem., Int. Ed. 2014, DOI: 10.1002/anie.201406637.

(33) Kresse, G.; Furthmüller, J. Phys. Rev. B 1996, 54, 11169-11186.

(34) Kresse, G.; Furthmüller, J. Comput. Mater. Sci. 1996, 6, 15-50.

(35) Blöchl, P. E. Phys. Rev. B 1994, 50, 17953-17979.

(36) Perdew, J. P.; Burke, K.; Ernzerhof, M. Phys. Rev. Lett. 1996, 77, $3865-3868$.

(37) Dudarev, S. L.; Botton, G. A.; Savrasov, S. Y.; Humphreys, C. J.; Sutton, A. P. Phys. Rev. B 1998, 57, 1505-1509.

(38) Fabris, S.; de Gironcoli, S.; Baroni, S.; Vicario, G.; Balducci, G. Phys. Rev. B 2005, 71, 041102-4.

(39) Kümmerle, E. A.; Heger, G. J. Solid State Chem. 1999, 147, 485500.

(40) Heyden, A.; Bell, A. T.; Keil, F. J. J. Chem. Phys. 2005, 123, 224101.

(41) Henkelman, G.; Uberuaga, B. P.; Jónsson, H. J. Chem. Phys. 2000, 113, 9901-9904.

(42) Krukau, A. V.; Vydrov, O. A.; Izmaylov, A. F.; Scuseria, G. E. J. Chem. Phys. 2006, 125, 224106.

(43) Wang, X.-G.; Chaka, A.; Scheffler, M. Phys. Rev. Lett. 2000, 84, $3650-3653$.

(44) Ganduglia-Pirovano, M. V.; Da Silva, J. L. F.; Sauer, J. Phys. Rev. Lett. 2009, 102, 026101.

(45) For an example of this type of analysis see: García-Melchor, M.; Gorelsky, S. I.; Woo, T. K. Chem.-Eur. J. 2011, 17, 13847-13853 and references therein..

(46) Farra, R.; García-Melchor, M.; Eichelbaum, M.; Hashagen, M.; Frandsen, W.; Allan, J.; Girgsdies, F.; Szentmiklósi, L.; López, N.; Teschner, D. ACS Catal. 2013, 3, 2256-2268.

(47) Vilé, G.; Wrabetz, S.; Floryan, L.; Schuster, M. E.; Girgsdies, F.; Teschner, D.; Pérez-Ramírez, J. ChemCatChem 2014, 6, 1928-1934. 